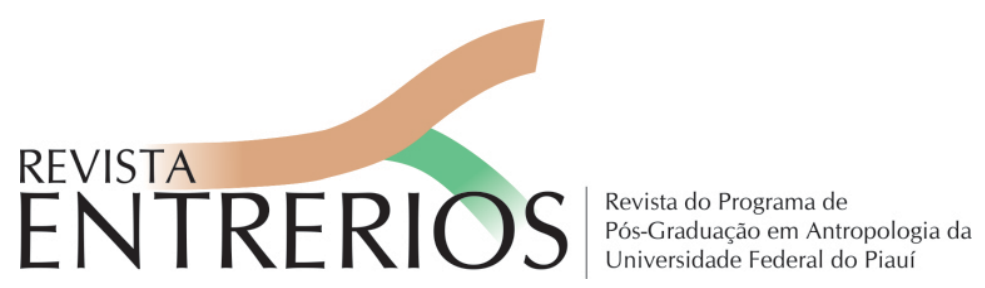

\title{
Pesquisa em Antropologia da Educação, diálogo de saberes e interculturalidade: entrevista com Dr. Gunther Dietz e Dra. Laura Selene Mateos Cortés.
}

\author{
Raimundo Nonato Ferreira do Nascimento \\ Universidade Federal do Piauí - UFPI \\ nonatorr.33@gmail.com \\ Marion Teodósio de Quadros \\ Universidade Federal de Pernambuco - UFPE \\ marionteodisio@yahoo.com \\ Vânia Fialho \\ Universidade de Pernambuco - UFPE \\ vania.antropologia@gmail.com
}

Neste número da Revista EntreRios, temos a satisfação de publicar uma entrevista realizada com dois profissionais da Antropologia mexicana, o Dr. Gunther Dietz e a Dra. Laura Selene Mateos Cortez, pelos organizadores deste dossiê, que nos aportam grandes contribuições na reflexão sobre a pesquisa antropológica no campo da educação ${ }^{1}$.

1 Nessa entrevista, damos continuidade a um diálogo que se iniciou no ano 2011, por ocasião da realização de uma experiência acadêmica de doutorado sanduíche realizada por Raimundo Nonato no Instituto de Investigação em Educação da Universidade Veracruzana na cidade de Xalapa, sob a orientação do Dr. Gunther Dietz. Na oportunidade, o Prof. Raimundo Nonato, originalmente vinculado ao Programa de Pós-Graduação em Antropologia na UFPE sob a orientação da professora Vânia Fialho, também conheceu a Doutora Laura Selene, com que manteve contato e diálogos. Uma das atividades de intercâmbio realizadas, durante a estadia do prof. Raimundo Nonato, foi o estabelecimento de contato entre o Prof Gunther e a Profa. Marion, que se encontrava em estágio pós-doutoral na Flórida, EUA. Desse contato resultou uma visita da Profa. Marion à Universidade Veracruzana onde participou de um seminário disciplinar. Em 2016, o Prof. Gunther, juntamente com a Profa. Marion e a Profa. Neusa Gusmão, organizaram um dossiê intitulado “Antropologia, Educação, Alteridades e Desigualdades", na Revista Anthropológicas, do Programa de Pòs-Graduação em Antropologia da UFPE. A relação com os entrevistados foi ainda fortalecida com a experiência de doutorado sanduíche, de outra doutoranda do PPGA/UFPE na Universidade Veracruzana. Hosana Celi de Oliveira e Santos, que também se encontrava sob a orientação da Professora Vânia Fialho na UFPE, esteve vinculada aos estudos e pesquisas do Professor Gunther no período de abril a agosto de 2017. Desde então, as trocas têm se intensificado, e se tornado cada vez mais profícuas e oxalá consigamos estabelecer novas parcerias de trabalho. 
O Doutor Gunther Dietz possui Doutorado em Antropologia pela Universidade de Hamburgo (Alemanha), com uma vasta experiência na docência nas mais diversas universidades, dentre a mais importantes destacamos: Universidade de Hamburgo (Alemanha), Universidade de Granada (Espanha), Universidade Aalborg (Dinamarca), Universidade Gent (Bélgica). Atualmente é Investigador Titular no Instituto de Investigações em Educação da Universidade Veracruzana -UV, em Xalapa, México. Também é membro do Sistema Nacional de Investigadores, do Conselho Mexicano de Investigação Educativa, da Academia Mexicana de Ciências e da International Association for Intercultural Education (IAIE).

A Doutora Laura por sua vez, possui Doutorado em Antropologia Social pela Universidade de Granada (Espanha), e realizou estagio pós-doutoral no Centro Interdisciplinar de Estudos Avançados (CIEA) do Programa de Estudo Pós-doutoral PEP-UNTREF (Argentina, Buenos Aires), em 2015. É Professora -Investigadora titular do Instituto de Investigação em Educação da Universidade Veracruzana e membro do Sistema Nacional de Investigadores de México.

No conjunto de questões que propusemos ao Dr. Gunther e a Dra Loura, nos apresentam a importância do trabalho antropológico no campo da educação. Ao longo da conversa, os autores nos falam de suas trajetórias enquanto pesquisadores bem como das razões pelas quais elegeram a diversidade em contextos educativos como campo de estudo. Além disso, nos aportam uma importante análise da constituição do campo da Antropologia da educação no México, destacando as especificidades desta e suas contribuições para outros países da América Latina. Por fim, abordam a temática da interculturalidade e educação intercultural, enfatizando a importância dessa proposta educativa como possibilidade de uma educação que respeite, valorize e promova a diversidade.

EntreRios: Para comenzar, nos gustaría agradecerle su disponibilidad por aceptar nuestra invitación a participar en esta conversación. ¿Podrían contarnos un poco sobre sus trayectorias como investigadores, destacando las razones que los llevaron a seguir este camino de investigación con la diversidad (étnica, social, cultural, religiosa y de género) en la interfaz con la an tropología y la educación?

Laura Selene: Una parte de mi familia es originaria de Oaxaca, pertenece a la cultura zapoteca del Istmo de Tehuantepec, y la otra parte es náhuatl de la Huasteca veracruzana. Crecí en el sur de Veracruz, en la ciudad petrolera de Minatitlán, marcada por migraciones internas desde Oaxaca a Veracruz y por tanto por una diversidad lingüística, cultural y étnica que hasta la fecha caracteriza al sur de Veracruz, un lugar de paso y de encuentro entre los pueblos náhuatl, popoluca, zapoteco, mestizo y afroveracruzano, entre otros. Pero también ha sido siempre un entorno industrial y petrolero, con muchas desigualdades socioeconómicas, es una tierra marcada por cacicazgos históricos, por el PRI como el viejo partido-estado y por el corporativismo que lo caracterizaba. Para "respirar aires de cambio" logré emigrar a Xalapa, la capital de Veracruz, donde mi primera formación académica fue en filosofía, carrera que estudié en la Universidad Veracruzana. Pero pronto me volvieron a interesar estas temáticas de diversidad de las que provenía, y así en el marco de mis estudios de posgrado en antropología social, que realicé en la Universidad de Granada, en España, me inicié en mis primeras investigaciones etnográficas, de vuelta en el sur de Veracruz - en la maestría (Diploma de Estudios Avanzadas se llamaba en aquel entonces) analicé “La compresión de los discursos políticos en comunidades campesinas. Aproximaciones teórico- metodológicas”, centrándome sobre todo en el análisis de los discursos de líderes partidistas y caciquiles frente a la población rural campesina. 
Posteriormente, pasé del análisis de políticas en general a estudiar los emergentes discursos interculturales que estaban llegando a Veracruz mediante la creación de nuevas instituciones de educación superior para los pueblos originarios de Veracruz; y así fue que acabé en el doctorado analizando "La migración transnacional del discurso intercultural" en instituciones educativas veracruzanas.

Gunther Dietz: En mi caso, la diversidad cultural siempre me ha llamado la atención desde que en mi infancia pasé siete años en el sur de Chile, en la Araucanía, y posteriormente sufrí el "choque cultural" al regresar a Alemania, un país que creía conocer, pero que me parecía más raro y exótico que el sur de Chile. Y luego más adelante gracias a algunas vivencias con comunidades migrantes y refugiadas en Hamburgo, en el norte de Alemania, y posteriormente con comunidades gitanas tanto como musulmanas en el sur de España la diversidad en su rico abanico de diversidades internas, la "diversidad de diversidades", se volvió una especie de leitmotiv de mis investigaciones. En México pude trabajar un tiempo con actores educativos purhépecha en Michoacán y desde 2007 con actores nahuas, popoluca, totonacos y tepehua en Veracruz. En este proceso estuve transitando u oscilando entre la antropología, que es mi formación original, y la pedagogía, las ciencias de la educación, mi ámbito actual de trabajo. Creo que ambos, Laura Selene y yo, estamos en este ir y venir constante, interdisciplinario, entre una mirada antropológica y otra educativa.

EntreRios: Considerando la Antropología de la Educación como un campo de estudio importante, ¿podrían contarnos sobre el establecimiento de este campo en México?, ¿cuáles fueron los desafíos teóricos y metodológicos para su consolidación?

Laura Selene: En mi país la antropología, como sabes, tiene una larga, secular tradición, y en comparación con otros países, sobre todo europeos, se caracteriza por un fuerte papel de la aplicación, de la antropología aplicada. Noté cuando estudiaba el posgrado en la Universidad de Granada que hay en varios contextos europeos tradiciones muy "exotistas", casi "esotéricas" de estudiar temas que le interesan al/a la antropólogo/a, pero que para nada tienen una mirada de aplicación, de compromiso social. Eso en México por fortuna no es así, por lo menos yo no lo he experimentado así. Y este énfasis en lo aplicado, en la praxis antropológica se combina con un gran interés por impactar en el ámbito educativo: en México desde la Revolución de 1917 y desde la institucionalización de la disciplina antropológica quienes se dedican a la antropología se dedican a la educación: no únicamente en el sentido de estudiar, etnografiar procesos educativos, sino sobre todo porque su labor antropológica ha de impactar en la sociedad, en la política, en las relaciones interétnicas, interculturales. El indigenismo ha sido una de las épocas clásicas de la antropología de la educación mexicana.

Gunther Dietz: Y esta fortaleza de la antropología de la educación, que la caracteriza con altibajos, por supuesto - desde Manuel Gamio en la posrevolución, los años del cardenismo etc., origina también uno de sus principales desafíos: su relación con el estado-nación mexicano, su relación con el poder. Un siglo después de que surgiera esta simbiosis entre el estado y la antropología nuestra disciplina está desplegando formas diversas de relacionarse y de comprometerse con otros actores más allá del estado. Pero ha sido un proceso lento, conflictivo y también laboralmente difícil, dado que el estado hasta hace pocas décadas era prácticamente el único empleador de antropólogas y antropólogos. Un legado de esta tradición aplicada, indigenista de la antropología mexicana es que a veces cuesta defender y justificar proyectos de investigación de más largo aliento, de más larga duración y que no tengan una agencia gubernamental como patrocinadora o "encargadora" de la investigación. 
EntreRios: ¿Cuáles serían las particularidades del debate sobre la consolidación de la Antropología de la Educación en México?, ¿cómo difiere de otros países latinoamericanos?, ¿ustedes consideran que hay alguna relación entre este campo de estudio en México y los estudios de Antropología de la Educación en Brasil?

Laura Selene: La consolidación de la antropología de la educación mexicana vino de la mano de la consolidación de las políticas indigenistas de integración de los pueblos originarios al estado-nación. Grandes proyectos de "aculturación planificada", de "castellanización", más tarde de "bilingüismo transitorio" y luego de educación bilingüe-bicultural, como se les llamaba en los años setentas e inicios de ochentas, eran el producto de la confluencia entre la antropología y la lingüística aplicada a las políticas indigenistas. No es éste el lugar para discutir o evaluar éxitos versus fracasos del indigenismo en cada una de sus épocas - algunas más asimiladoras, otras más integradoras, con más o menos participación o negociación con los propios actores indígenas -, pero es obvio que sin este papel de la antropología no se habría dado la importante y destacable consolidación institucional: una Escuela Nacional de Antropología e Historia, un Museo Nacional de Antropología, un gran abanico de facultades de antropología así como de reconocidos centros de investigación antropológica, en los cuales casi siempre hay colegas dedicadas/os también a la antropología de la educación.

Gunther Dietz: Y este grado de consolidación no lo he visto en otros países ni latinoamericanos ni europeos. La antropología europea, como sabes, tiene un fuerte legado colonial y poscolonial, de estudiar "otredades" en las colonias y excolonias de los antiguos imperios, pero tras la descolonización administrativa (que no real ni epistémica) observo que estas antropologías europeas pierden su gran referente empírico. Sí, hay una rica antropología europea practicada en Europa, pero siguen siendo en muchos casos lo que en Alemania se llaman "disciplinas orquídeas", lujos académicos sin impacto real en sus respectivas sociedades y contextos. La relevancia que la antropología, en general, y la antropología de la educación, en particular, adquieren en América Latina es mucho mayor, precisamente por su papel en la construcción del estado y de la relación entre estado y sociedad en el contexto poscolonial y contemporáneo. En México, en Colombia, en otros países andinos, también en Brasil, la antropología de la educación juega este papel fundacional, podríamos decir, un papel que en países europeos como Francia han jugado otras ciencias sociales fundacionales, como la demografía, la estadística y la sociología: el papel de conocer la sociedad para la mirada del estado. México y Brasil en este sentido tienen un legado común, ya que el indigenismo en ambos casos ha impulsado el desarrollo de nuestra disciplina, pero a la vez lo ha precondicionado, a veces incluso predeterminado. Hay diversidades que apenas estudiamos en nuestros países porque no las percibe nuestro "lente indigenista".

EntreRios: La diversidad cultural siempre ha sido el campo privilegiado de la Antropología. En este sentido, nos gustaría que comentaran sobre sus experiencias con la investigación sobre la diversidad (cultural, étnica, religiosa y de género), ¿cuál es la importancia de abordar estos temas en el campo de la educación?, ¿cómo la an tropología puede contribuir en este debate?

Laura Selene: Precisamente por lo que Gunther mencionaba ahora, es indispensable abrir la mirada, ampliar la mirada hacia todo tipo de diversidades, para no reproducir sesgos indigenistas, para no simplificar, reproduciendo tópicos. Observo en la antropología de la educación mexicana y latinoamericana el peligro de una especie de ecuación: lo diverso igual a lo indígena, o lo intercultural como sinónimo de lo indígena o de lo étnico. 
Y si este sesgo se produce en la antropología de la educación y de ahí se pasa al resto de la investigación educativa, entonces rápidamente nos vamos a encontrar con propuestas, enfoques y modelos educativos de "atención a la diversidad" que lo que logran es sobre-visibilizar cierto tipo de diversidad (étnica, indígena, en este caso), mientras invisibilizan otras diversidades, la clase social, la desigualdad de género, la discriminación religiosa etc. En nuestras investigaciones tanto como en nuestros diseños pedagógicos estamos obligados a insistir en el carácter no esencial, sino construido y negociado de las identidades, de las diversidades, para no (auto-) folklorizar, sino para partir de los propios actores, con sus siempre muy variopintas y cambiantes predilecciones en cuanto a lo que es "propio" versus lo que es "ajeno" en cada contexto, en cada momento.

Gunther Dietz: Y por eso lo que en la Universidad Veracruzana y en nuestro grupo de investigación llamamos "Estudios Interculturales" es una combinación entre un programa teórico-metodológico de estudio comparativo y siempre crítico de la diversidad de diversidades, pero que no únicamente analizamos como diversidades, sino simultáneamente procuramos descifrar como diferencias - en el sentido más micro de políticas de identidad horizontales de los propios actores con los que trabajamos - y como desigualdades verticales producto de estructuras macro que se reproducen en el contexto de persistentes regímenes de colonialidad, de patriarcado y de capitalismo, como los denomina Boaventura de Sousa Santos. La antropología de la educación hoy no puede limitarse a una mirada microscópica hacia el aula escolar, sino que tiene que estudiar "hacia abajo" y "hacia arriba" a la vez - algo que se complica aún más si además tienes que reconocer que como antropóloga/o de la educación no solamente investigas, sino que transformas la realidad que investigas. Por eso, hablamos a menudo de una metodología de "doble reflexividad", en la que la reflexividad característica de la mirada antropológica es complementada, profundizada y cuestionada por la reflexividad propia de las y los actores educativos con quiénes colaboramos.

EntreRios: ¿Cómo ustedes evalúan las politicas públicas para el reconocimiento, apreciación y promoción de la diversidad (social, cultural, étnica, de género) promovida por los gobiernos de México y Brasil, como, por ejemplo, las reformas educativas?

Laura Selene: El hecho de que en las políticas públicas de educación, pero también de sanidad, de justicia, de bienestar etc., comience a reflejarse lentamente el reconocimiento y la promoción de la diversidad constituye un gran logro de los propios colectivos afectados, discriminados e históricamente excluidos. Han sido los movimientos sociales de estos colectivos los que en las últimas décadas lograron - primero a nivel internacional y mucho más tarde y lentamente a nivel nacional y regional - que se generen cambios constitucionales y legislativos. Este proceso de reconocimiento ha sido no solamente muy lento, sino que está lleno de progresos y retrocesos. En la época clásica del multiculturalismo neoliberal, Charles Hale ha denominado este proceso paulatino e reconocimiento como el del "indio permitido", que tiene como la otra cara de la moneda al indio prohibido: se permite la diversidad cultural y lingüística, a menudo folklorizada, etnificada, pero se prohíbe la autonomía, la autodeterminación territorial, el control de los recursos. La antropología requiere hoy en día formular alianzas explícitas y claras con los movimientos, con las organizaciones para pasar de la "concesión" del derecho a la diversidad al pleno ejercicio de este derecho, a su aplicación a nivel local y regional. Hay un abismo, una brecha de implementación de derechos concedidos, pero no ejercidos...

Gunther Dietz: Y en tiempos como los actuales de pandemia, con descaradas políticas de recortes sociales, disfrazadas bajo el manto retórico de la "austeridad", me temo que se profundizará esta brecha. 
Desde la antropología de la educación requerimos estrategias multi-niveles: por una parte, tenemos que afianzar nuestras alianzas con los actores con quiénes trabajamos, las comunidades, los pueblos originarios, las poblaciones migrantes, refugiadas y/o transmigrantes, para lograr desde abajo la exigibilidad de los derechos reconocidos constitucionalmente y en los tratados internacionales: derechos de consulta previa, libre e informada, derecho a una educación propia, en tu propia lengua, con pertinencia cultural, derecho a la libre movilidad de las personas, derecho a la inclusión de personas con capacidades funcionales o intelectuales diferentes etc. Y por otra parte, como académicos/as necesitamos incrementar nuestro "impacto" en la sociedad y en la política pública: consultando, asesorando, negociando, convenciendo a quiénes son responsables de las políticas públicas de que éstas tienen que ser repensadas de forma "inductiva", i.e. pensadas de abajo hacia arriba, y no al revés, como es costumbre en nuestros países poscoloniales, centralistas, urbanocéntricos, racistas, que suelen generar políticas desde el imaginario, no desde la realidad vivida en nuestras sociedades latinoamericanas contemporáneas.

EntreRios: Basado en sus experiencias de investigación con diversidad étnica, religiosa, cultural y de género, tanto en Europa como en México, ¿cómo nos ayudarían estas realidades investigadas a pensar en la educación para la diversidad?

Laura Selene: Tengo más experiencia en México que en Europa, pero tras muchos y muy fructíferos intercambios con colegas del Laboratorio de Estudios Interculturales de la Universidad de Granada, del Grupo INTER de la Universidad Nacional a Distancia de Madrid así como con la educación intercultural desarrollada en la Universidad de Hamburgo, constato que hay experiencias muy compatibles, comunes: desde la antropología de la educación y desde la investigación educativa pretendemos repensar y rediseñar la escuela contemporánea para adecuarla a la diversidad real, a la que caracteriza nuestras diversas y cambiantes sociedades, pero en esta pretensión, en este intento nos encontramos con una resiliencia institucional muy fuerte, con una gran resistencia al cambio: la escuela pensada e inventada en el siglo XIX tiene que transformarse en algo completamente diferente para poder albergar la diversidad, para poder abrirse a la diversidad, para aprovecharla.

Gunther Dietz: Coincido con lo que menciona Laura Selene, esto a veces nos lleva a cierto pesimismo en relación a las tareas pendientes. Ha sido muy difícil tanto en contextos europeos como en regiones latinoamericanas convencer a "hacedores/as" de políticas educativas "soltar las riendas", dotarle a cada institución no solamente de los recursos necesarios, sino de la libertad y creatividad necesaria a nivel local para reinventar la escuela desde abajo, que es la tarea que tendríamos. Las escuelas pueden atender diferentes tipos de diversidades siempre y cuando se les deje margen de maniobra, cuando se les permita ser creativos, improvisar, aprender, intercambiarse con otras escuelas. María Bertely llamaba estos procesos los "interaprendizajes" horizontales que son necesarios para la tan aclamada, pero tan poco practicada innovación educativa. Necesitamos establecer, promover y mantener redes de intercambio horizontal entre escuelas, entre comunidades de aprendizaje, sin que medien jerárquicamente ministerios, jefaturas y toda esta parafernalia decimonónica y barroca que todavía caracteriza la institución educativa de cuño occidental.

EntreRios: ¿Cómo la teoría de la migración del discurso transnacional, presentada por la Dra. Laura Selene Mateos Cortés, en el libro "La migración transnacional del discurso intercultural", puede contribuir para teorizar sobre la migración de los discursos y conocimiento en el campo de la antropología delaeducación? 
Laura Selene: El libro que mencionas, fruto de mi tesis doctoral, surge de la paradoja de que cuando comienzo a analizar qué entienden por interculturalidad, por diversidad, por discurso intercultural los diferentes actores educativos en Veracruz - maestros/s en escuelas normales formadoras de profesorado, asesores/as técnico-pedagógicos/as regionales y docentes creadoras/os de la Universidad Veracruzana Intercultural - me doy cuenta que estos discursos no son completamente propios de estos actores, pero tampoco son totalmente ajenos, impuestos a ellos. Mi análisis de los diferentes discursos interculturales me revela que hay un proceso de transferencia - en este caso entre España y México - de modelos interculturales, pero también hay una apropiación y resignificación local, que refleja tradiciones y cauces indigenistas, comunalistas y/o ecologistas que aportan los propios actores. Se trata de una migración transnacional porque determinados organismos bi- o multilaterales están fomentando explícitamente la exportación/importación de modelos educativos, no solamente interculturales, y este fenómeno es para mí muy revelador de la situación que vivimos, de la colonialidad norte-sur que persiste y que nos hace copiar, mimetizar a veces modelos que provienen de otros contextos, pero que "por moda" acabamos importando y aplicando. Para la antropología de la educación, considero que mi aportación consiste en desvelar estos procesos más globales y transnacionales - no tan fáciles de identificar a nivel micro-etnográfico -, para lo cual necesitamos una mirada etnográfica multisituada, no sedentaria, sino igualmente migrante. Si migran los modelos y discursos, la antropología de la educación también tiene que migrar para analizar estos discursos, compararlos críticamente y contribuir con ello a retroalimentar a los propios actores locales afectados en su capacidad de resistencia y resignificación ante los discursos hegemónicos.

EntreRios: Actualmente están trabajando en un proyecto llamado Diálogo de Saberes (InterSaberes). Teniendo en cuenta que hubo un proceso de jerarquización del conocimiento durante siglos, ¿cómo han estado pensando este debate y cómo, en teoría, están abordando este problema?

Gunther Dietz: InterSaberes es un proyecto que hemos desarrollado desde 2007 como un acompañamiento etnográfico-colaborativo a los principales actores de la Universidad Veracruzana Intercultural (UVI), una novedosa entidad académica de la propia Universidad Veracruzana que ofrece programas educativos de licenciatura y maestría para jóvenes rurales e indígenas en sus propias regiones de origen y con un enfoque intercultural. En el proyecto logramos acompañar primero a docentes y estudiantes, luego a miembros de sus comunidades locales y por último a egresadas/os de la UVI para conocer cómo se estaban dando los pretendidos diálogos de saberes entre lo académico y lo comunitario, entre lo áulico y lo vivencial, entre la teoría y la praxis. Ha sido un proceso largo y sumamente enriquecedor para todas las partes, ya que hemos podido variar y transitar ente fases más etnográficas clásicas, más "extractivas", si se quiere, de observación participante, de entrevistas, grupos focales y registros de actividades dentro y fuera de la UVI, cuyos resultados luego transferimos a "foros intersaberes" con los propios actores, para practicar la ya mencionada doble reflexividad, para co-interpretar las experiencias, para co-teorizar lo que entendemos por interculturalidad, por diversidad de diversidades, por diálogos de saberes.

Laura Selene: Y en este proceso también nos hemos dado cuenta que la así llamada universidad intercultural puede generar nuevas prácticas, puede ampliar el canon de saberes, puede reconocer y normalizar el uso de las lenguas originarias, pero que no es fácil transformar la propia institución universitaria. Los saberes textuales, escriturales de origen occidental, plasmados en libros de texto, en una pléyade de teóricos (casi siempre varones blancos europeos), tienen tal peso frente al carácter oral, flexible, comunitario y cotidiano de los saberes- 
-haceres propios de los pueblos que a menudo no se da un diálogo de saberes en términos equitativos. Pudimos analizar estos procesos e intentos de diálogo en el pluralismo jurídico entre derecho positivo mexicano y derecho consuetudinario comunitario, en la salud intercultural entre medicina "blanca" y medicina tradicional, en la conservación de especies silvestres así como en la socialización comunitaria y la educación escolar - y en todos estos casos persiste una jerarquía y una tensión entre ambas fuentes de saberes. Sin embargo, lo que nos llena de optimismo es presenciar cómo no tanto el personal académico de la UVI - sumamente preparado y comprometido con estos difíciles retos -, sino sobre todo las y los jóvenes estudiantes y egresados se van convirtiendo en un nuevo tipo de profesional intercultural, en mediadores/as y traductores/as entre estos saberes jerárquicamente opuestos. En proyectos comunitarios, en iniciativas no-gubernamentales, en actividades municipales las y los jóvenes profesionales van nutriéndose tanto de sus saberes comunitarios, locales y familiares como de sus conocimientos académicos en su desempeño laboral y de sus papeles comunitarios - como defensores/as del territorio, como diseñadores/as de proyectos locales y como traductores/as e intérpretes que median en instituciones de salud, de procuración de justicia o de educación escolarizada y formación docente.

EntreRios: De acuerdo con sus experiencias en universidades interculturales, que se basan en el "diálogo del conocimiento"; ¿podríamos considerar que este modelo de universidad sería una posibilidad de institucionalizar la descolonización del ser, el conocimiento y el poder? Siendo las universidades interculturales un modelo para la descolonización del conocimiento, ¿podría este modelo expandirse más allá de las relaciones con los pueblos indígenas?

Laura Selene: Lo que en México llamamos universidades interculturales abarca un abanico de diferentes instituciones educativas de nueva creación; a veces son universidades que dependen de gobiernos estatales, regionales con escasa autonomía y fuertes problemas de continuidad política e institucional, en otros casos son universidades creadas por ONGs o por iniciativas locales, y en nuestro caso, en Veracruz, la UVI es una universidad gestada al interior de una universidad pública y autónoma ya consolidada. En este último caso ha habido algunos avances en la institucionalización de lo que mencionas como descolonización del ser, del poder y del saber, ya que al tener como "paraguas" a una institución autónoma, que no sufra constantemente de intromisiones políticas partidistas, confesionales o de otra índole, la UVI ha podido consolidar una cultura propia del diálogo de saberes a su interior, con autoridades nombradas por su conocimiento en el tema (y no por favores políticos, como en otros casos), con consejos consultivos de comunidades implicadas a largo plazo en el proyecto y con una planta docente joven y creativa, que se está basificando y está practicando - poco a poco y no extenso de problemas y obstáculos - la interculturalidad en sus actividades de docencia, de investigación y de vinculación local.

Gunther Dietz: Y este tipo de universidad intercultural, que no es un modelo único o homogéneo, sí debería servir no como prototipo a imitar, sino como un ejemplo del cual aprender también para otros procesos de innovación universitaria. Más allá del ámbito de los pueblos originarios, todas las instituciones de educación superior tienen un legado eurocéntrico, racista y colonial, pero también un sesgo urbanocéntrico, androcéntrico y jerarquizante que impide dialogar con saberes no académicos. La universidad del siglo XXI requiere de nuevos mecanismos de diálogo, de compromiso y de co-labor con actores de la sociedad - junto con estos actores se generarán nuevos aprendizajes y nuevos conocimientos, algo que le permitirá sobrevivir en su función epistémica, cognitiva. Sin esta interculturalización radical de sus funciones de docencia, de investigación, de vinculación, de aprovechamiento del multilingüismo y de la interculturalidad, me temo que la universidad tal como la conocemos tiene los días contados... 
EntreRios: ¿Cómo o qué, las experiencias de investigación en el área de antropología de la educación en México, pueden aportar a las investigaciones brasileñas y viceversa?

Laura Selene: Cuando hacemos encuentros internacionales, cuando generamos miradas comparativas es cuando realmente aprendemos tanto de lo propio como del o ajeno: identificamos lo específico del contexto propio, local, a la vez que identificamos similitudes y diferencias con los contextos ajenos. Precisamente por la proliferación de discursos y modelos supuestamente "universales", globales en la educación y en las reformas educativas dictadas desde arriba, requerimos de esta constante contrastación entre nuestros contextos nacionales. Brasil y México, por sus experiencias históricas, por sus similitudes en cuanto a la antropología y el indigenismo, pero también por sus divergencias - pienso en las experiencias afrobrasileñas, de las que tanto podríamos y deberíamos aprender en México - son en este sentido "hermanas" predilectas para tales intercambios.

Gunther Dietz: Y estos intercambios, estas miradas cruzadas no deberían agotarse en, acotarse a actores académicos, sino incluir a actores con quiénes venimos colaborando en nuestros proyectos a veces desde hace décadas. Recuerdo un encuentro pequeño, improvisado, pero muy rico que logramos llevar a cabo en Veracruz entre actores comunitarios y académicos de Veracruz (nahuas en su mayoría), de Chile (mapuche en su mayoría) y de Arotearoa/Nueva Zelanda (maori en su mayoría) - el intercambiar miradas, experiencias, éxitos tanto como fracasos nos permitió no solamente diseñar nuevas vetas de colaboración internacional, sino a la vez identificar como en un doble espejo lo que es particular - para bien o para mal - de la experiencia propia, de la trayectoria propia.

EntreRios: Muchas gracias! 